\title{
BMJ Open Optimal Thromboprophylaxis in Elderly Chinese Patients with Atrial Fibrillation (ChiOTEAF) registry: protocol for a prospective, observational nationwide cohort study
}

\author{
Yutao Guo, ${ }^{1}$ Yutang Wang, ${ }^{1}$ Xiaoying Li, ${ }^{1}$ Zaoliang Shan, ${ }^{1}$ Xiangmin Shi, ${ }^{1}$ \\ Guorong Xi, ${ }^{2}$ Gregory Y H Lip, ${ }^{3}$ On behalf of the ChiOTEAF Registry Investigators
}

To cite: Guo $Y$, Wang $Y$,

Li X, et al. Optimal

Thromboprophylaxis in Elderly Chinese Patients with Atrial Fibrillation (ChiOTEAF) registry: protocol for a prospective, observational nationwide cohort study. BMJ Open 2018;8:e020191. doi:10.1136/ bmjopen-2017-020191

- Prepublication history and additional material for this paper are available online. To view these files, please visit the journal online (http://dx.doi. org/10.1136/bmjopen-2017020191).

Received 21 0ctober 2017 Revised 16 December 2017 Accepted 12 January 2018

Check for updates

${ }^{1}$ Department of Cardiology, Chinese PLA General Hospital, Beijing, China

${ }^{2}$ Health Division of Guard Bureau, Chinese PLA General Staff Department, Beijing, China ${ }^{3}$ Institute of Cardiovascular Sciences, University of Birmingham, Birmingham, UK

Correspondence to Dr Yutang Wang; wyt301@yeah.net

\section{ABSTRACT}

Introduction Atrial fibrillation (AF) is a worldwide healthcare burden that is associated with the ageing population. Elderly patients with AF with multiple comorbidities usually present with a high risk of thromboembolism and bleeding. Limited prospective data are available from Asian cohorts on the epidemiology and complications of AF. The present prospective cohort study aims to explore contemporary antithrombotic strategies among the elderly Chinese population in the new era of non-vitamin $\mathrm{K}$ antagonist oral anticoagulants and to compare the clinical characteristics and outcomes between Chinese and European AF populations.

Methods and analysis The Optimal Thromboprophylaxis in Elderly Chinese Patients with Atrial Fibrillation

(ChiOTEAF) registry will recruit 5000 patients with AF over 65 years of age in China. AF-related risks, including stroke/ systemic thromboembolism and bleeding outcomes, will be assessed. Medical history, risk factors, demographic information and management will be collected at baseline, and clinical events during 1 year follow-up will be recorded. Follow-up will be conducted for at least 1 year and then annually thereafter. As our registry has a common protocol to the European Society of Cardiology EURObservational Research Programme AF general registry programme, preplanned analyses comparing the clinical profiles and outcomes will be performed. The ChiOTEAF registry offers an opportunity to provide a better understanding of the clinical profiles and adverse outcomes of patients with AF in China and allow for comparisons with a contemporary European population. Ethics and dissemination Ethics approval was granted by the Central Medical Ethic Committee of Chinese PLA General Hospital (approval no S2014-065-01). The (inter)national research presentations, peer-reviewed publications and media coverage of the research will be sued for dissemination of the results.

\section{INTRODUCTION}

Atrial fibrillation (AF) is evident as a worldwide epidemic in the 2013 WHO Global Burden of Disease database. ${ }^{1} \mathrm{AF}$ and its major

\section{Strengths and limitations of this study}

- The strengths of the Optimal Thromboprophylaxis in Elderly Chinese Patients with Atrial Fibrillation registry include the large contemporary setting in the era of non-vitamin $\mathrm{K}$ antagonist oral anticoagulants, in a prospective, multicentre, observational, real-world nationwide study of the elderly Chinese population.

- Another strength is the aligned definitions of clinical features and comorbidities, as well as a common case report form with the European Society of Cardiology EURObservational Research Programme Atrial Fibrillation (EORP-AF) general registry.

- The alignment with EORP-AF will allow direct comparison between different countries and/or regional populations for the clinical epidemiology of AF.

- As limitations common to observational cohort studies, some inadequacy of data recording/capture and selection bias may occur. The inclusion of consecutive patients and the use of high grade hospitals in China, as well as data monitoring, would limit these issues.

complication, stroke/systemic thromboembolism, have a profound impact on disability and mortality, and the condition is particularly serious in the elderly population. ${ }^{2}$

The management of AF has had many updates and new developments over recent years, ${ }^{3-5}$ with the introduction of clinical risk scores (ie, Congestive heart failure, Hypertension, Age, Diabetes, Stroke $\left(\mathrm{CHADS}_{2}\right)$; Congestive heart failure, Hypertension, Age $\geq 75$, Diabetes, Stroke, Vascular disease, Age 65-74 and Sex category (female) ( $\left.\mathrm{CHA}_{2} \mathrm{DS}_{2} \mathrm{VASc}\right)$ and Hypertension, Abnormal renal/liver function, Stroke, Bleeding history, Labile international normalised ratio, Elderly, Drugs) and non-vitamin $\mathrm{K}$ antagonist oral anticoagulants (NOACs). Recent reports suggest that 
approximately $80 \%$ of patients with AF in Europe and $55 \%$ of patients with AF in North America use oral anticoagulants. ${ }^{6}$ In China, the use of warfarin was only $7 \%$ as reported in the Chinese Society of Cardiology survey published in $2004^{8}$ and $14 \%$ in the more recent 2013 study. ${ }^{9}$ Thus, we need more data on the contemporary management and treatment of AF in elderly Chinese patients in the new era of NOACs.

NOACs have shown advantages over warfarin for stroke prevention in pivotal randomised clinical trials (RCTs), ${ }^{10}$ with better efficacy and safety seen in Asian subgroups of those RCTs compared with non-Asians. ${ }^{11}$ Of note, Asians are more susceptible to haemorrhagic stroke, with a fourfold increased risk for intracranial haemorrhage associated with warfarin, when compared with the white population. ${ }^{1213}$

The pattern of various comorbidities may differ between Asians and non-Asians, which may have implications for adverse outcomes related to this arrhythmia. For example, patients with $\mathrm{AF}$ who have atherosclerotic disease (ie, coronary artery disease $(\mathrm{CAD})$ and peripheral artery disease (PAD)) have increased composite outcomes of cardiovascular death, myocardial infarction and stroke compared with patients with $\mathrm{AF}$ without atherosclerotic disease. ${ }^{14}$ This special population would benefit more from thromboprophylaxis, but they may be at higher risk for bleeding. ${ }^{15}$ The presence of PAD also seems to confer a particularly high risk of stroke in Asian patients with $\mathrm{AF}^{16}$

The present prospective cohort study (Optimal Thromboprophylaxis in Elderly Chinese Patients with Atrial Fibrillation (ChiOTEAF) registry) aims to explore contemporary antithrombotic strategies among the elderly Chinese population in the new era of NOACs, and it focuses on the optimal antithrombotic therapy in patients with AF with high-risk factors. Second, we aim to compare the clinical characteristics and outcomes between the Chinese and European AF populations. The latter is possible as our registry has a common protocol to the European Society of Cardiology EURObservational Research Programme AF (EORP-AF) general registry programme, so preplanned analyses comparing the clinical profiles and outcomes will be performed.

\section{Primary and secondary hypotheses}

The primary hypothesis is to analyse the relationship between antithrombotic management of $\mathrm{AF}$ and cardiovascular events at 6 months and 12 months in the included patients with $\mathrm{AF}$.

The secondary hypotheses are to explore the regional differences in antithrombotic therapies used, as well as adverse outcomes over follow-up, between the European and Chinese cohorts.

\section{METHODS}

The ChiOTEAF registry is a prospective, multicentre, observational registry. All of the patients will give written informed consent.

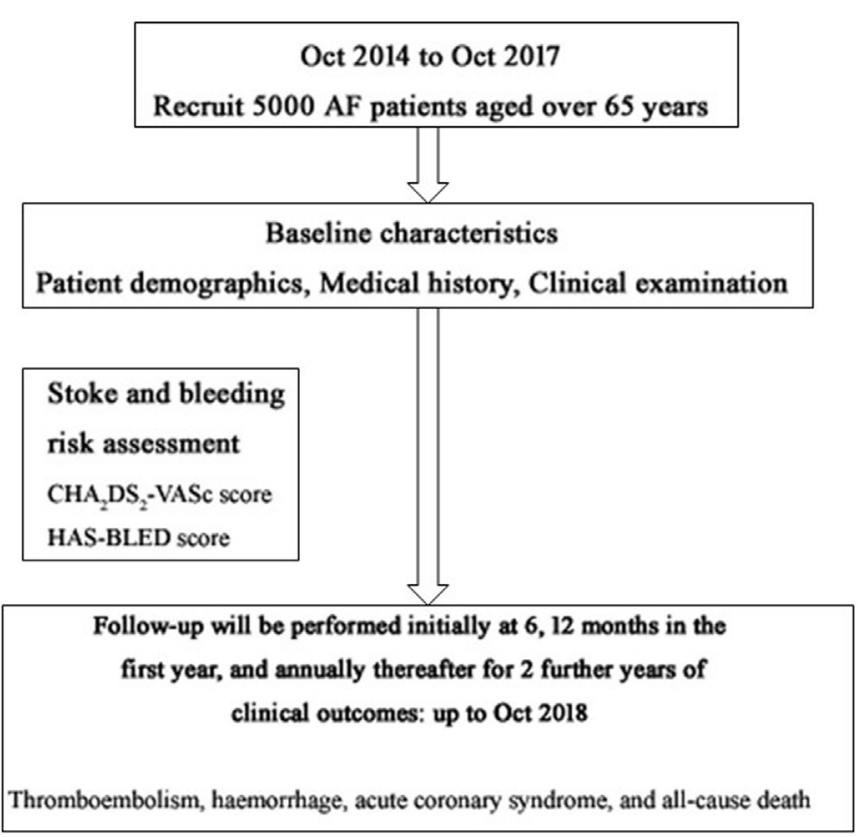

Figure 1 Flow chart. $\mathrm{CHA}_{2} \mathrm{DS}_{2}$-VASc, Congestive heart failure, Hypertension, Age $\geq 75$, Diabetes, Stroke, Vascular disease, Age 65-74 and Sex category (female); HAS-BLED, Hypertension, Abnormal renal/liver function, Stroke, Bleeding history, Labile international normalised ratio, Elderly, Drugs.

\section{Study population}

Inclusion criteria include the following: (1) patients aged $\geq 65$ years; (2) ECG/Holter diagnosis of AF; (3) the qualifying episode of AF should have occurred within 1 year before the date of screening and AF is the primary or secondary diagnosis, that is, the current admission/visit can be due to other reasons; (4) patient adherence to the study and (5) Patient Informed Consent form has been signed. Exclusion criteria are as follows: (1) no ECG with AF recorded (12-lead ECG, Holter recording, external event recorder or implantable loop recorder), (2) only atrial flutter recorded, (3) the qualifying episode of $\mathrm{AF}$ occurred more than 1 year before the date of screening and (4) participation in a clinical trial.

Patients will be consecutively recruited at each site to ensure representative inclusion of the overall population in each practice setting in China. Enrolment will occur between 1 October 2014 and 31 October 2017. Study flow chart is shown in figure 1.

\section{Evaluations}

The patients will be evaluated at baseline for demographic and medical characteristics. Follow-up will be performed initially at 6 and 12 months in the first year and annually thereafter for two additional years to ascertain the antithrombotic therapy and the outcome (table 1).

\section{Study outcomes}

Adverse events, including thromboembolism, haemorrhage, acute coronary syndrome (ACS) and all-cause death, will be recorded during the follow-up visits. Thromboembolism includes ischaemic stroke, transient 
Table 1 Evaluations at baseline and follow-up visits

\begin{tabular}{|c|c|c|}
\hline Baseline & 6-month and 12-month visits & 24-month and 36-month visits \\
\hline
\end{tabular}

ACS, acute coronary syndrome; APTT, activated partial thromboplastin time; FIB, fibrinogen; INR, international normalised ratio; PT, prothrombin time; TT, thrombin time.

ischaemic attack, pulmonary embolism, deep vein thromboembolism, other thromboembolism (eg, peripheral embolism, atrial thrombus and left atrial appendage thrombus).

Haemorrhage events include intracranial haemorrhage and extracranial bleeding. Intracranial haemorrhage is defined as intracerebral haemorrhage, subarachnoid haemorrhage, acute subdural haematoma, chronic subdural haematoma, epidural haemorrhage and subdural haematoma. Major bleeding is defined as clinically overt bleeding accompanied by one or more of the following: a decrease in the blood haemoglobin level of more than $2.0 \mathrm{~g} / \mathrm{dL}$ or more over a 24-hour period, the need for a transfusion of 2 or more units of packed red cells, the need for corrective surgery or bleeding at a critical site (extracranial, intraspinal, intraocular, pericardial, intra-articular, intramuscular with compartment syndrome or retroperitoneal).

ACS includes unstable angina, non-ST-segment elevation myocardial infarction (NSTEMI) and ST-segment elevation myocardial infarction (STEMI). All-cause death includes cardiac death, vascular death and non-cardiovascular death. Cardiac death includes death caused by STEMI/NSTEMI, heart failure, arrhythmia, cardiac perforation/tamponade and other deaths of cardiac origin. Vascular death includes death ascribed to ischaemic stroke, haemorrhagic stroke, systemic bleeding, peripheral embolism and pulmonary embolism.

\section{Study setting and site selection}

Mainly cardiologists, together with specialists in neurology and surgeons, were invited to participate in the study.
Site selection is designed to provide a distribution across regions in China so it is representative of the Chinese $\mathrm{AF}$ population. Study sites were selected among hospitals in China that would provide good quality medical services and correct corresponding diagnoses. A pilot investigation was initially carried out to obtain general information on the rate of patients with $\mathrm{AF}$ by age in the possible sites before the full ChiOTREAF registry commenced. The investigation showed that the distribution rates of $\mathrm{AF}$ were approximately $15 \%, 18 \%, 44 \%$ and $23 \%$ in the age groups of 50-64 years, 65-74 years, 75-84 years and over 85 years, respectively. Study sites were selected based on the pilot investigation and site quality. In total, 44 sites from 20 provinces are involved in the present registry study.

\section{Data management}

All of the site data will be collected locally and forwarded to the central clinical research database. The database will be monitored in real time by a data management centre. Data management for the ChiOTEAF registry will be performed by an independent third party (Westat, Rockville, Maryland, USA). The independent third-party audit will mainly monitor the following points: health, safety and that the relevant rights of subjects are protected; the sites carry out the study according to protocol; the data collected are true and accurate and the site staff and facility meet the protocol requirements.

\section{Statistical approach}

Data will be summarised using mean (SD), medians (range) for continuous data and counts (percentages) 
for categorical data. Continuous variables will be tested for distribution by the Kolmogorov-Smirnov test. Those with a normal distribution will be presented as a mean with SD and analysed by t-test or Analysis of Variance test. Data with a non-normal distribution will be presented as median with IQR and will be analysed by non-parametric methods. The comparison of discrete variables will be performed via the $\mathrm{X}^{2}$ test. A Cox proportional hazard model on the outcomes will be performed to test the impact of covariates (patient characteristics, physician characteristics, risk scores and antithrombotic drugs). The analysis will be conducted for age groups, particularly for patients $\geq 75$ years old to clarify the association between age and outcomes. All of the statistical analyses will be considered significant at the $5 \%$ confidence limit using two-sided tests or two-sided CIs.

Planned analyses include the following:

- description of patient characteristics and risk factors at baseline, changes in the thromboembolic/bleeding risk profiles and changes in the antithrombotic treatment during follow-up, as well as compliance of antithrombotic therapy related to the risk assessment;

- evaluation of the 6-month and 12-month cardiovascular event rates (stroke, systemic thromboembolism, major bleeding and cardiovascular death) in relation to different antithrombotic therapies used for the $\mathrm{AF}$ population;

- comparison of clinical features, use of oral anticoagulation therapies and clinical outcomes between patients with AF in Europe and those in China.

\section{Determination of sample size}

Assuming an annual rate of stroke/systemic thromboembolism of $6.0 \%$ in the non-anticoagulated $\mathrm{AF}$ population compared with $2.0 \%$ in anticoagulated patients, ${ }^{9}$ we will need $n=424$ anticoagulated patients to test a difference in outcome, with a power of $80 \%$ and $1-\mathrm{a}=0.05$. Assuming the rate of anticoagulant use is $30 \%$ in the population, we will need 1413 patients. The withdrawal rate is assumed to be $10 \%$ during the first year, thus the sample size for this study will need to be at least 1554 patients with 1 year follow-up to show a crude difference with anticoagulant use. Nevertheless, the present study is observational, and some patients will be recruited to allow us to have sufficient information on subgroups of patients to do further analysis. Hence, an estimated sample size of 5000 enrolled patients is required.

\section{DISCUSSION}

The ChiOTEAF registry will update the clinical epidemiology of AF in the current era of NOACs, clarify the current antithrombotic strategies used in China and compare AF management between Western and Chinese populations.

Clinical epidemiological studies on AF in China over the past decades have demonstrated that the rate of warfarin use was low, with $2.7 \%-21.2 \%$ in community-based studies and $6.7 \%-18 \%$ in hospital-based studies, whereas the reported rates of stroke/thromboembolism ranged from $4.1 \%$ to $17.5 \%$ (table 2). ${ }^{28} 917-29$ More recently, various international studies involving Asia showed a much higher rate of anticoagulant use in those countries, between $35 \%$ and $55 \%$ (table 3) ${ }^{60-33}$ Nevertheless, the current profile of anticoagulant management remains unclear in China, especially since the availability of NOACs has changed the landscape of AF management worldwide. Updated information on AF management in China is needed given the huge AF burden in the world's most populous country.

Although RCTs have confirmed the safety of NOACs, many issues need to be addressed in 'real-world' practice, such as gastrointestinal bleeding. Indeed, elderly patients are usually at high risk of both thromboembolism and bleeding. The ChiOTEAF registry provides an opportunity to observe the effectiveness and safety of NOACs in a high-risk Chinese population. Furthermore, cardiovascular risk factors are changing over time. For example, vascular disease (myocardial infarction and peripheral vascular disease) is an independent risk factor that contributes to the stroke/thromboembolism. ${ }^{734}$ In several observational AF cohorts, $19 \%-47 \%$ of patients with $\mathrm{AF}$ have $\mathrm{CAD}$ and $6 \%-11 \%$ have $\mathrm{PAD} .{ }^{6735}$ The prevalence of atherosclerotic vascular disease is more common in elderly patients.

A treatment gap of AF management exists between Western and Eastern populations despite advances in AF management. The direct comparison of Western and Eastern populations from different studies published thus far cannot be reliably performed due to different study designs. While limited studies have investigated ethnic differences across different countries, even the international registry studies involving different countries have not been designed to reveal the differences (table 3).

The ChiOTEAF registry is designed to have aligned definitions of clinical features and comorbidities with a common case report form (CRF) and protocol with the EORP-AF registry, which makes the two registries comparable. EORP-AF and ChiOTEAF are two independent contemporary registries, carried out in Europe and China, respectively. Thus, differences in AF management can be compared and analysed in Western and Chinese populations, which is a preplanned analysis. With the aligned definitions, the ChiOTEAF registry could also be potentially compared with similar registries conducted in Iran and by the Asia Pacific Heart Rhythm Society using the EORP-AF protocol and CRF. Thus, this novel study design cannot only investigate the clinical epidemiology of China, but it can also make the direct comparison among different country/regional populations practical.

\section{Limitations}

The ChiOTEAF registry is an observational, real-world cohort study. The AF population will be recruited across China, but as possible limitations common to observational cohort studies, inadequacy of data recording/ capture and selection bias may occur. To avoid this as 
Table 2 Clinical epidemiology of atrial fibrillation in China

\begin{tabular}{|c|c|c|c|c|c|c|}
\hline Author & Study date/place & Design/patients & $\begin{array}{l}\text { AF prevalence/ } \\
\text { incidence }\end{array}$ & Warfarin, \% & Aspirin, \% & Stroke prevalence, $\%$ \\
\hline \multicolumn{7}{|c|}{ Community-based studies } \\
\hline Zhou and $\mathrm{Hu}^{17}$ & 2003 & $\begin{array}{l}\text { China mainland: } \\
\text { prospective, cross- } \\
\text { sectional } \\
n=29079 \\
\text { Age } \geq 30 \text { years }\end{array}$ & $\begin{array}{l}\text { Overall: } 0.77 \% \\
\text { Male: } 0.91 \% \\
\text { Female: } 0.63 \%\end{array}$ & $2.7 \%$ & $39.7 \%$ & $12.9 \%$ \\
\hline Zhang et $a l^{18}$ & 2004 & $\begin{array}{l}\text { China mainland: } \\
\text { prospective, random } \\
\text { cluster sampling } \\
n=18615 \\
\text { Age } \geq 35 \text { years }\end{array}$ & $\begin{array}{l}\text { Overall: } 1.04 \% \\
\text { Male: } 1.09 \% \\
\text { Female: } 1.00 \%\end{array}$ & - & - & $13.4 \%$ \\
\hline Long et $a l^{19}$ & 2003-2006 & $\begin{array}{l}\text { China mainland: } \\
\text { prospective, cross- } \\
\text { sectional } n=19964 \\
\text { Age } \geq 50 \text { years }\end{array}$ & $\begin{array}{l}\text { Overall: } 0.80 \% \\
\text { Male: } 1.15 \% \\
\text { Female: } 0.66 \%\end{array}$ & - & - & - \\
\hline Mu et $a l^{20}$ & 2009 & $\begin{array}{l}\text { China mainland: } \\
\text { prospective } \\
n=30000 \\
\text { Mean age } 50.5 \\
(30.5) \text { years }\end{array}$ & $\begin{array}{l}\text { Overall: } 2.83 \% \\
\text { Male: } 5.66 \% \\
\text { Female: } 2.87 \%\end{array}$ & - & - & - \\
\hline Guo et $a l^{221}$ & $\begin{array}{l}2001-2012 \text { with } \\
\text { follow-up for } \\
11 \text { years/China } \\
\text { mainland }\end{array}$ & $\begin{array}{l}\text { Retrospective, } \\
n=471446 \\
\text { Age } \geq 20 \text { years }\end{array}$ & $\begin{array}{l}\text { Prevalence: } \\
\text { Overall: } 0.27 \% \\
\text { Male: } 0.28 \% \\
\text { Female: } 0.26 \% \\
\text { Incidence: } \\
\text { Overall: } 0.05 / 100 \\
\text { person-years }\end{array}$ & $4.1 \%$ & $32.3 \%$ & Annual stroke rate: $6 \%$ \\
\hline Li et $a /^{36}$ & $\begin{array}{l}2006-2011 \text { with a } \\
\text { median } 3.8 \text { years } \\
\text { of follow-up }\end{array}$ & $\begin{array}{l}\text { Prospective, } \\
n=4750 \\
\text { Age } \geq 60 \text { years }\end{array}$ & $\begin{array}{l}\text { Incidence: } \\
\text { Overall: 0.049/100 } \\
\text { person-years }\end{array}$ & $1.0 \%$ & $4.8 \%$ & - \\
\hline Chien et $a l^{22}$ & $\begin{array}{l}\text { 1990-2000, with } \\
\text { follow-up of } \\
\text { 9years }\end{array}$ & $\begin{array}{l}\text { Taiwan: } \\
\text { prospective } \\
\mathrm{n}=3580 \\
\text { Age } \geq 35 \text { years }\end{array}$ & $\begin{array}{l}\text { Overall: } 1.07 \% \\
\text { Male: } 1.4 \% \\
\text { Female: } 0.7 \%\end{array}$ & - & - & Prior stroke rate: $2.6 \%$ \\
\hline Lin et $a l^{23}$ & $\begin{array}{l}\text { July } 2003-J u n e \\
2004\end{array}$ & $\begin{array}{l}\text { Taiwan: } \\
\text { retrospective; data from } \\
\text { the Taiwanese National } \\
\text { Health Insurance } \\
\text { medical claims } \\
\text { databases } \\
n=39541 \\
\text { Mean age } \\
70.1 \pm 12.1 \text { years }\end{array}$ & - & $21.2 \%$ & $46.7 \%$ & $\begin{array}{l}\text { Previous } \\
\text { thromboembolism, } \\
15.0 \%\end{array}$ \\
\hline \multicolumn{7}{|c|}{ Hospital-based studies } \\
\hline $\begin{array}{l}\text { Society of } \\
\text { Cardiology, } \\
\text { Chinese Medical } \\
\text { Association }^{8}\end{array}$ & 1999-2001 & $\begin{array}{l}\text { China mainland: } \\
\text { retrospective } \\
n=9297 \\
\text { Age } 18-99 \text { years }\end{array}$ & $\begin{array}{l}\text { Incidence: } 7.9 \% \\
\text { per year }\end{array}$ & $6.6 \%$ & $57.9 \%$ & $17.5 \%$ \\
\hline $\begin{array}{l}\text { Sun et al; } \mathrm{Hu} \\
\text { et }\left.\mathrm{a}\right|^{24}\end{array}$ & $\begin{array}{l}\text { January 2000- } \\
\text { April } 2002\end{array}$ & $\begin{array}{l}\text { China mainland: } \\
\text { retrospective; } \\
n=3425 \\
\text { (with } \\
\text { NVAF) }\end{array}$ & - & $9.1 \%$ & $56 \%$ & $16.4 \%$ \\
\hline Guo et $a l^{25}$ & $\begin{array}{l}\text { January } 1995- \\
\text { May } 2015, \text { with } \\
\text { the observational } \\
\text { period of } 20 \text { years }\end{array}$ & $\begin{array}{l}\text { China mainland: } \\
\text { retrospective; } \\
n=4824 \\
\text { Mean age } 67 \text { years }\end{array}$ & - & $9.33 \%$ & $21.19 \%$ & $7.38 \%$ \\
\hline Guo et $a l^{926}$ & $\begin{array}{l}\text { November } \\
2007-J u l y ~ 2010, \\
\text { with follow-up of } \\
1.9 \text { years }\end{array}$ & $\begin{array}{l}\text { China mainland: } \\
\text { retrospective cohort } \\
\text { study; } \\
\mathrm{n}=1034 \\
\text { Median age } 75 \text { years }\end{array}$ & - & $14 \%$ & $\begin{array}{l}\text { Aspirin: } 39.3 \% \\
\text { Clopidogrel: } 10.7 \% \\
\text { Aspirin+clopidogrel: } 21.5 \%\end{array}$ & $\begin{array}{l}\text { Annual stroke/ } \\
\text { thromboembolism rate: } \\
4.5 \%\end{array}$ \\
\hline Yang et $a l^{27}$ & $\begin{array}{l}\text { November } 2008- \\
\text { October } 2011 \text {, } \\
\text { with follow-up of } \\
1 \text { year }\end{array}$ & $\begin{array}{l}\text { China mainland: } \\
\text { prospective cohort } \\
\text { study; } \\
\mathrm{n}=2016 \\
\text { Median age } 68 \text { years }\end{array}$ & - & $18 \%$ & - & $7.40 \%$ \\
\hline
\end{tabular}




\begin{tabular}{|c|c|c|c|c|c|c|}
\hline Author & Study date/place & Design/patients & $\begin{array}{l}\text { AF prevalence/ } \\
\text { incidence }\end{array}$ & Warfarin, \% & Aspirin, \% & Stroke prevalence, \% \\
\hline Li et $a l^{28}$ & $\begin{array}{l}\text { January 2008- } \\
\text { December } 2014\end{array}$ & $\begin{array}{l}\text { Hong Kong: } \\
\text { retrospective; } \\
n=2099 \\
\text { Mean age } 73 \text { years }\end{array}$ & - & $\begin{array}{l}\text { Warfarin: } 45.9 \% \\
\text { Rivaroxaban: } \\
31.9 \% \\
\text { Dabigatran: } 22.2 \%\end{array}$ & - & $\begin{array}{l}\text { Annual stroke incidence: } \\
4.10 \% / \text { year }\end{array}$ \\
\hline Lee et $\left.a\right|^{29}$ & 1997-2002 & $\begin{array}{l}\text { Taiwan: } \\
\text { retrospective } \\
n=162340 \\
\text { Mean age } 73 \text { years }\end{array}$ & $\begin{array}{l}\text { Overall incidence: } \\
\text { Annual mean } 127 \\
\text { per } 100000 \\
\text { Male: } 137 \\
\text { per } 100000 \\
\text { Female: } 116 \\
\text { per } 100000\end{array}$ & - & - & Prior stroke: $15 \%$ \\
\hline
\end{tabular}

AF, atrial fibrillation; NVAF, non-valvular atrial fibrillation.

Table 3 International studies of atrial fibrillation (including Asian/China subgroups)

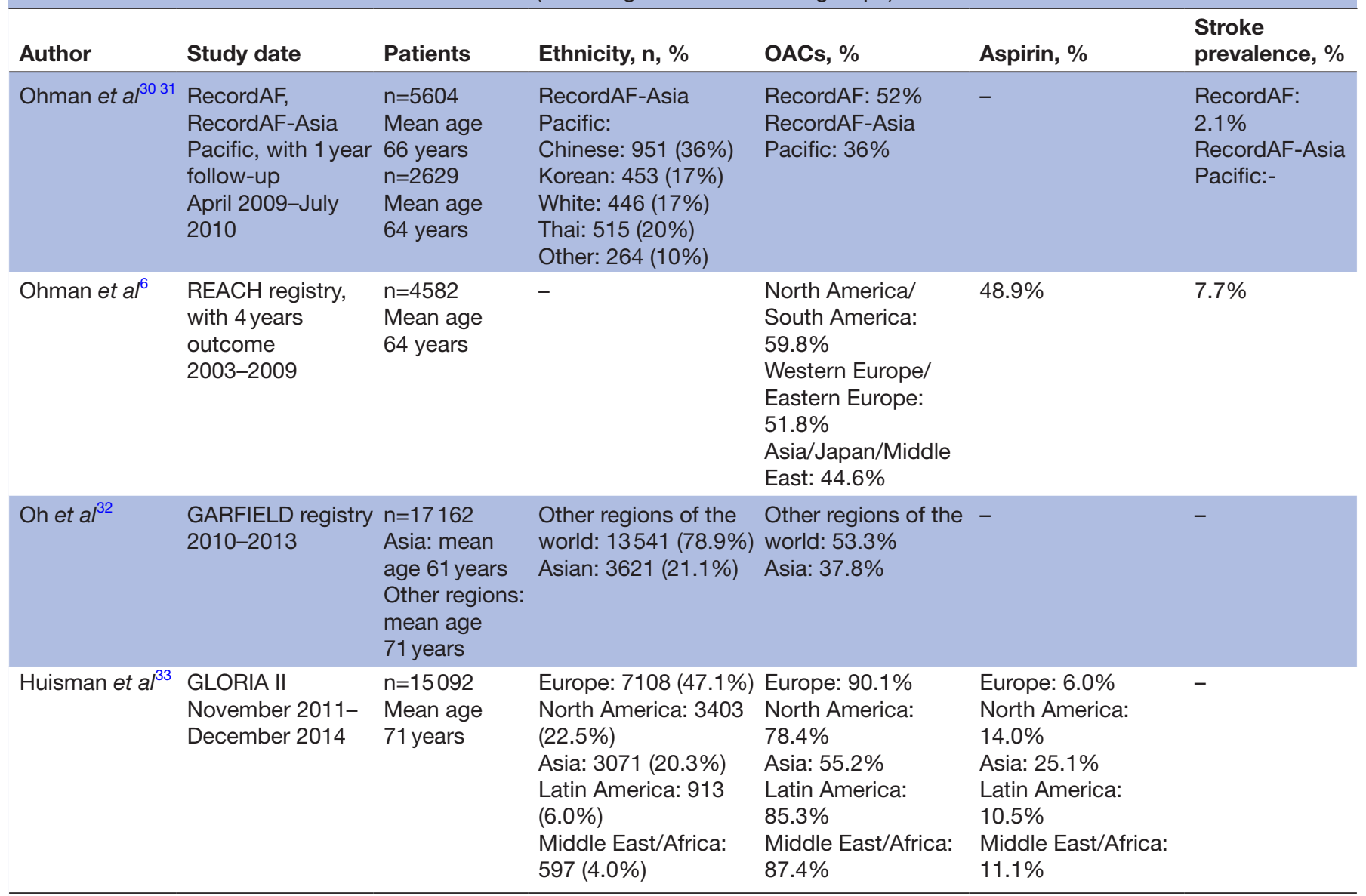

OAC, oral anticoagulant.

much as possible, site selection will be carried out among 2A and 3A Grade hospitals in China, which would guarantee a similarly high quality of medical services. In addition, the site selection was partly based on the pilot investigation, which will further be confirmed by data monitoring by a third-party contract research organisation through individual site assessment visits.

Acknowledgements We would like to greatly thank the EURObservational Research Programme (EORP) team, national coordinators and investigators for kindly cooperating with the ChIOTEAF registry to allow the comparative analysis between European and Chinese cohorts. Members of the Executive Steering
Committee, Steering Committee (national coordinators) and investigators are provided in the primary EORP-AF paper describing the baseline data.

Collaborators Academic Executive Steering Committee: Gregory Y H Lip, MD (Institute of Cardiovascular Sciences, University of Birmingham, United Kingdom (Co-Chair)); Xiaoying Li, MD, PhD (Department of Geriatric Cardiology, Chinese PLA General Hospital, Beijing, China (Co-Chair)); Yutang Wang, MD, PhD (Department of Geriatric Cardiology, Chinese PLA General Hospital, Beijing, China (Co-Chair)); Yundai Chen, PhD (Department of Cardiology, Chinese PLA General Hospital, Beijing, China); Changsheng Ma, MD, PhD (Department of Cardiology, Center for Atrial Fibrillation, Beijing Anzhen Hospital, Capital Medical University, Beijing, China); Shu Zhang, MD, PHD (Fuwai Hospital, Chinese Academy of Medical Sciences, Beijing, China); Congxin Huang, MD, PHD (RenMin Hospital, Wuhan University, Wuhan, China); Jiefu Yang, MD, PhD (Department of Cardiology, Beijing Hospital, 
Chinese Academy of Medical Sciences and Peking Union Medical College, Beijing, China); Meilin Liu (Department of Geriatrics, Peking University First Hospital, Beijing, China). Data Management Committee: Gregory Y H Lip, MD, PHD (Institute of Cardiovascular Sciences, University of Birmingham, United Kingdom); Yutao Guo, MD, PhD (Department of Geriatric Cardiology, Chinese PLA General Hospital, Beijing, China); Guangliang Shan, PhD (Department of Epidemiology and Statistics, Institute of Basic Medical Sciences, Chinese Academy of Medical Sciences and School of Basic Medicine, Peking Union Medical College, Beijing, China); Taixiang Wu, MD, PhD (Administrator of Chinese Clinical Trial Registry, Associate Professor of Clinical Epidemiology and Evidence-Based Medicine, West China Hospital, Sichuan University); Chen Yao, PhD (Associate Director, Peking University Clinical Research Institute, Beijing, China). Steering Committee Members: Changsheng Ma, MD, PhD (Anzhen Hospital, Capital Medical University, Beijing); Congchun Huang, MD, PhD (Air Force General Hospital, Beijing); Cuntai Zhang, MD, PhD (Tongji Hospital, Tongji Medical college, Huazhong University of Science \& Technology, Guangzhou); Dang Aiming, MD, PhD (Fuwai Hospital, Chinese Academy of Medical Sciences, Beijing); Dawei Qian, MD, PhD (Ji Lin Hospital, Ji Lin); Fakuan Tang, MD, PhD (PLA 309th Hospital, Beijing); Fang Wu, MD, PhD (Rui Jin Hospital, Tong University School of Medicine, Shanghai); Feng Liu, MD, PhD (First People's Hospital, Guangdong); Gexin Zhu, MD, PhD (The General Hospital, Tianjing Medical Hospital, Tianjing); Guo Yutao, MD, PhD (PLA General Hospital, Beijing); Guorong Xi, MD (Health Division of Guard Bureau, Chinese PLA General Staff Department, Beijing); Heng Dou, MD, PhD (Beijing Hospital, Beijing); Hou Cuihong, MD, PhD (Fuwai Hospital, Chinese Academy of Medical Sciences, Beijing); Hua Li, MD, PhD (The First Affiliated Hospital, Zhengzhou University, Zhejiang); Hui Han, MD, PhD (The First Affiliated Hospital, Harbin Medical University, Heilongjiang); Huiliang Liu, MD, PhD (Wujing General Hospital, Beijing); Jian Kong, MD, PhD (The First Affiliated Hospital, Ji Lin University, Ji Lin); Junxia Li, MD, PhD (Beijing PLA General Hospital, Beijing); Liang Zaoguang (The First Affiliated Hospital, Harbin Medical University, Heilongjiang); Liangyi Si, MD, PhD (Southwest Hospital, Chongqing); Liu Meilin, MD, PhD (The First Affiliated Hospital, Peking University First Hospital, Beijing); Liu Yanxia, MD (Shenyang General PLA Hospital); Liu Yu, MD (Yanggu People's Hospital, Shandong); Liu Zhiming, MD, PhD (Fuwai Hospital, Chinese Academy of Medical Sciences, Beijing); Luo Ma, MD, PhD (NAVY General Hospital, Beijing); Ming Li, MD, PhD (Beijing Friendship Hospital, Capital Medical University, Beijing); Qian Xiao, MD, PhD (First Affiliated Hospital, Chongqing Medical University, Chongqing); Qingwei Chen, MD, PhD (The Second Affiliated Hospital, Chongqing Medical University, Chongqing); Qiong Chen, MD, PhD Xiangya Hospital, Central South University, Hunan); Ren Xuejun, MD, PhD (Anzhen Hospital, Capital Medical University, Beijing); Shan Zhaoliang, MD, PhD (PLA General Hospital, Beijing); Shi Xiangming, MD, PhD (PLA General Hospital, Beijing); Shilian Hu, MD, PhD (Anhui Provincial Hospital, Anhui); Song Bai, MD, PhD (First Affiliated Hospital of Kunming Medical University, Kunming); Tianchang Li, MD, PhD (NAVY General Hospital, Beijing); Wang Lijuan, MD (Suqian People's hospital, Jiangsu); Wu Qiang, MD, PhD (Guizhou Provincial People's Hospital); Xianghu Wang, MD, PhD (Union Hospital, Tongji Medical College, Huazhong University of Science \& Technology, Guangzhou); Xiaojuan Bai, MD, PhD (Sheng Jing Hospital, China Medical University, Shengyang, Liaoning); Xiaoming Wang, MD, PhD (Xijing Hospital, Xian Xinchun Yang, MD, PhD Chao-Yang Hospital, Capital Medical University, Beijing); Xuan He, MD, PhD (Air Force General Hospital, Beijing); Xuejun Liu, MD, PhD (The First Affiliated Hospital, Shanxi Medical University, Shanxi); Yan Li, MD, PhD First (People's Hospital, Kunming, Yunnan); Yang Jiefu, MD, PhD (Beijing Hospital, Beijing); Yong Wang, MD, PhD (China-Japan Friendship Hospital, Beijing); Yunmei Yang, MD, PhD (The First Affiliated Hospital, Zhenjiang University, Zhejiang); Zeng Yuan, MD, PhD (PLA 306 Hospital); Zhang Shu, MD, PhD (Fuwai Hospital, Chinese Academy of Medical Sciences, Beijing); Zhang Wei, MD, PhD (Beijing PLA General Hospital, Beijing); Zhanyi Lin, MD, PhD (Guangdong General Hospital, Guangdong).

Contributors YG and GYHL had the main idea of the study and drafted the manuscript. YW, XL, ZS, XS and GX contributed to the design of the study and were involved in the editing of the manuscript. All of the authors have read and approved the final manuscript.

Funding The study was supported by Beijing Natural Science Foundation (Z141100002114050) and National Natural Science Foundation of China (H2501).

Competing interests GYHL is a consultant for Bayer/Janssen, BMS/Pfizer, Biotronik, Medtronic, Boehringer Ingelheim, Microlife and Daiichi Sankyo and a speaker for Bayer, BMS/Pfizer, Medtronic, Boehringer Ingelheim, Microlife, Roche and Daiichi Sankyo. No fees are received personally.

Patient consent Obtained.
Ethics approval The study was approved by the Central Medical Ethic Committee of Chinese PLA General Hospital, Beijing, China (approval no S2014-065-01) and local institutional review boards.

Provenance and peer review Not commissioned; externally peer reviewed.

Data sharing statement No additional data are available.

Open Access This is an Open Access article distributed in accordance with the Creative Commons Attribution Non Commercial (CC BY-NC 4.0) license, which permits others to distribute, remix, adapt, build upon this work non-commercially, and license their derivative works on different terms, provided the original work is properly cited and the use is non-commercial. See: http://creativecommons.org/ licenses/by-nc/4.0/

(c) Article author(s) (or their employer(s) unless otherwise stated in the text of the article) 2018. All rights reserved. No commercial use is permitted unless otherwise expressly granted.

\section{REFERENCES}

1. Chugh SS, Havmoeller R, Narayanan K, et al. Worldwide epidemiology of atrial fibrillation: a global burden of disease 2010 study. Circulation 2014;129:837-47.

2. Guo $\mathrm{Y}$, Tian $\mathrm{Y}$, Wang $\mathrm{H}$, et al. Prevalence, incidence, and lifetime risk of atrial fibrillation in China: new insights into the global burden of atrial fibrillation. Chest 2015;147:109-19.

3. Camm AJ, Lip GY, De Caterina R, et al. 2012 focused update of the esc guidelines for the management of atrial fibrillation: an update of the 2010 esc guidelines for the management of atrial fibrillation. Developed with the special contribution of the european heart rhythm association. Eur Heart J 2012;33:2719-47.

4. Heidbuchel $\mathrm{H}$, Verhamme $\mathrm{P}$, Alings $\mathrm{M}$, et al. European heart rhythm association practical guide on the use of new oral anticoagulants in patients with non-valvular atrial fibrillation. Europace 2013;15:625-51.

5. Anderson JL, Halperin JL, Albert NM, et al. Management of patients with atrial fibrillation (compilation of 2006 ACCF/AHA/ESC and 2011 ACCF/AHA/HRS recommendations): a report of the American college of cardiology/American heart association task force on practice guidelines. J Am Coll Cardiol 2013;61:1935-44.

6. Lip GY, Laroche C, Dan GA, et al. A prospective survey in European society of cardiology member countries of atrial fibrillation management: baseline results of EURObservational Research Programme Atrial Fibrillation (EORP-AF) Pilot General Registry. Europace 2014;16:308-19.

7. Chan PS, Maddox TM, Tang F, et al. Practice-level variation in warfarin use among outpatients with atrial fibrillation (from the NCDR PINNACLE program). Am J Cardiol 2011;108:1136-40.

8. Society of Cardiology, Chinese Medical Association. Retrospective investigation of hospitalized patients with atrial fibrillation in mainland China. Chin Med J 2004;117:1763-7.

9. Guo Y, Apostolakis S, Blann AD, et al. Validation of contemporary stroke and bleeding risk stratification scores in non-anticoagulated Chinese patients with atrial fibrillation. Int J Cardiol 2013;168:904-9.

10. Ruff CT, Giugliano RP, Braunwald E, et al. Comparison of the efficacy and safety of new oral anticoagulants with warfarin in patients with atrial fibrillation: a meta-analysis of randomised trials. Lancet 2014;383:955-62.

11. Wang KL, Lip GY, Lin SJ, et al. Non-vitamin K antagonist oral anticoagulants for stroke prevention in asian patients with nonvalvular atrial fibrillation: meta-analysis. Stroke 2015;46:2555-61.

12. van Asch CJ, Luitse MJ, Rinkel GJ, et al. Incidence, case fatality, and functional outcome of intracerebral haemorrhage over time, according to age, sex, and ethnic origin: a systematic review and meta-analysis. Lancet Neurol 2010;9:167-76.

13. Shen AY, Yao JF, Brar SS, et al. Racial/ethnic differences in the risk of intracranial hemorrhage among patients with atrial fibrillation. J Am Coll Cardiol 2007;50:309-15.

14. Ruff CT, Bhatt DL, Steg PG, et al. Long-term cardiovascular outcomes in patients with atrial fibrillation and atherothrombosis in the REACH Registry. Int $\mathrm{J}$ Cardiol 2014;170:413-8.

15. Gladstone DJ, Bui E, Fang J, et al. Potentially preventable strokes in high-risk patients with atrial fibrillation who are not adequately anticoagulated. Stroke 2009;40:235-40.

16. Lin LY, Lee CH, Yu CC, Cc Y, et al. Risk factors and incidence of ischemic stroke in Taiwanese with nonvalvular atrial fibrillation- a nation wide database analysis. Atherosclerosis 2011;217:292-5.

17. Zhou Z, Hu D. An epidemiological study on the prevalence of atrial fibrillation in the Chinese population of mainland China. J Epidemiol 2008;18:209-16. 
18. Zhang X, Zhang S, Li Y, et al. Association of obesity and atrial fibrillation among middle-aged and elderly Chinese. Int J Obes 2009;33:1318-25.

19. Long MJ, Jiang CQ, Lam TH, et al. Atrial fibrillation and obesity among older Chinese: the guangzhou biobank cohort study. Int $J$ Cardiol 2011;148:48-52.

20. Mu HY, Qiu P, Lu WH, et al. [Electrocardiogram minnesota codings from 30000 adult cases with Kazakh ethnicity in Xinjiang, China]. Zhonghua Liu Xing Bing Xue Za Zhi 2010;31:451-4.

21. Guo $\mathrm{Y}$, Wang $\mathrm{H}$, Tian $\mathrm{Y}$, et al. Time trends of aspirin and warfarin use on stroke and bleeding events in Chinese patients with new-onset atrial fibrillation. Chest 2015;148:62-72.

22. Chien KL, Su TC, Hsu HC, et al. Atrial fibrillation prevalence, incidence and risk of stroke and all-cause death among Chinese. Int J Cardiol 2010;139:173-80.

23. Lin LJ, Cheng $\mathrm{MH}$, Lee $\mathrm{CH}$, et al. Compliance with antithrombotic prescribing guidelines for patients with atrial fibrillation-a nationwide descriptive study in Taiwan. Clin Ther 2008;30:1726-36.

24. Hu DY, Sun YH, Zhou ZQ, et al. [Risk factors for stroke in Chinese with non valvular atrial fibrillation: a case-control study]. Zhonghua Nei Ke Za Zhi 2003;42:157-61.

25. Guo YT, Zhang Y, Shi XM, et al. Assessing bleeding risk in 4824 Asian patients with atrial fibrillation: the Beijing PLA hospital atrial fibrillation project. Sci Rep 2016;6:31755

26. Guo Y, Pisters R, Apostolakis S, et al. Stroke risk and suboptimal thromboprophylaxis in Chinese patients with atrial fibrillation: would the novel oral anticoagulants have an impact? Int $J$ Cardiol 2013;168:515-22.

27. Yang YM, Shao XH, Zhu J, et al. Risk factors and incidence of stroke and MACE in Chinese atrial fibrillation patients presenting to emergency departments: a national wide database analysis. Int $J$ Cardiol 2014;173:242-7.

28. Li WH, Huang D, Chiang CE, et al. Efficacy and safety of dabigatran, rivaroxaban, and warfarin for stroke prevention in Chinese patients with atrial fibrillation: the Hong Kong atrial fibrillation project. Clin Cardiol 2017:40:222-9.

29. Lee CH, Liu PY, Tsai LM, et al. Characteristics of hospitalized patients with atrial fibrillation in Taiwan: a nationwide observation. Am J Med 2007;120:819.e1-7.

30. Camm AJ, Breithardt G, Crijns H, et al. Real-life observations of clinical outcomes with rhythm- and rate-control therapies for atrial fibrillation RECORDAF (Registry on Cardiac Rhythm Disorders Assessing the Control of Atrial Fibrillation). J Am Coll Cardiol 2011;58:493-501.

31. Amerena J, Chen SA, Sriratanasathavorn C, et al. Insights into management of atrial fibrillation in Asia Pacific gained from baseline data from registry on cardiac rhythm disORDers (RecordAF-Asia Pacific [AP]) registry. Am J Cardiol 2012:109:378-82

32. Oh S, Goto S, Accetta G, et al. Vitamin K antagonist control in patients with atrial fibrillation in Asia compared with other regions of the world: real-world data from the GARFIELD-AF registry. Int $J$ Cardiol 2016;223:543-7.

33. Huisman MV, Rothman KJ, Paquette M, et al. The changing landscape for stroke prevention in af: findings from the GLORIA-AF registry phase 2. J Am Coll Cardiol 2017;69:777-85.

34. Anandasundaram B, Lane DA, Apostolakis S, et al. The impact of atherosclerotic vascular disease in predicting a stroke, thromboembolism and mortality in atrial fibrillation patients: a systematic review. J Thromb Haemost 2013;11:975-87.

35. Kakkar AK, Mueller I, Bassand JP, et al. Risk profiles and antithrombotic treatment of patients newly diagnosed with atrial fibrillation at risk of stroke: perspectives from the international, observational, prospective GARFIELD registry. PLoS One 2013;8:e63479.

36. Li LH, Sheng CS, Hu BC, et al. The prevalence, incidence, management and risks of atrial fibrillation in an elderly Chinese population: a prospective study. BMC Cardiovasc Disord 2015;15:31. 